\title{
ANALISIS KEBUTUHAN RUANG PARKIR KENDARAAN RODA DUA DI KAMPUS UNISKA MAB BANJARMASIN
}

\author{
Adhi Surya \\ Dosen Prodi (S-1) Teknik Sipil, Fakultas Teknik, Uniska MAB \\ Jalan Adhyaksa No. 2, Banjarmasin, Kalimantan Selatan 70123 \\ E-mail: adhisurya1998@gmail.com/HP +6282116726469
}

\begin{abstract}
ABSTRAK
Banjarmasin sebagai salah satu kota dengan kepadatan penduduk yang cukup tinggi menyebabkan peningkatan dalam aspek trasportasi dengan setiap harinya kemacetan yang sering terjadi menandakan bahwa pemakaian kendaraan di kota banjarmasin meningkat dengan cepat, dengan meningkatnya volume lalu lintas kendaraan maka dibutuhkan suatu ruang parkir untuk kendaraan. Universitas Islam Kalimantan Muhammad Arsyad Al Banjari (UNISKA MAB) Banjarmasin adalah salah satu tujuan daripada mahasiswa dari berbagai daerah, mulai dari kota Banjarmasin sendiri sampai dari luar kota, dengan demikian setiap mahasiswa, dosen dan karyawan menggunakan transportasi sendiri-sendiri, mulai dengan transportasi umum sampai kendaraan pribadi. Kendala dari salah satu transportasi tersebut adalah kendaraa pribadi, dimana UNISKA harus menyediakan ruang parkir untuk kendaraan mahasiswa, dosen dan karyawan. Semakin bertambahnya pengguna kendaraan pribadi maka semakin banyaknya ruang yang harus disediakan untuk kebutuhan parkir. Sebelum adanya kebijakan pemerintah Kota Banjarmasin dalam hal ini Dinas Perhubungan melakukan larangan parkir dibahu jalan sepanjang Jalan Adhyaksa mengakibatkan semakin berkurangnya lahan parkir yang ada untuk mahasiswa, dosen dan karyawan. Dari pihak kampus setelah disediakan lahan untuk parkir, kini mahasiswa dan dosen dapat parkir di tempat tersebut. Tetapi pada kenyataannya lahan parkir itu masih tidak mampu menampung kendaraan roda dua mahasiswa, dosen dan karyawan untuk itu penelitian ini bertujuan untuk menganalisis kebutuhan ruang parkir kendaraan roda dua di kampus UNISKA MAB Banjarmasin.
\end{abstract}

Kata Kunci : Analisis Kebutuhan Ruang Parkir Kendaraan Roda Dua dan Kampus UNISKA MAB Banjarmasin

\section{ABSTRACK}

The city of Banjarmasin as one of the cities with a high population density causes an increase in transportation aspects with the frequent traffic jams which indicate that the use of vehicles in the city of Banjarmasin is increasing rapidly, with the increasing volume of vehicle traffic, a parking space for vehicles is needed. Kalimantan Islamic University Muhammad Arsyad Al Banjari (UNISKA MAB) Banjarmasin is one of the destinations of students from various regions, starting from the city of Banjarmasin itself to from outside the city, thus each student, lecturer and employee uses their own transportation, starting with public 
transportation to private vehicles. The obstacle of one of these transportation is a private vehicle, where UNISKA must provide parking space for vehicles for students, lecturers and employees. The increasing number of private vehicle users, the more space that must be provided for parking needs. Before the Banjarmasin City Government's policy in this case the Department of Transportation did a parking ban on the roads along Adhyaksa Street resulting in the reduction of available parking spaces for students, lecturers and employees. From the campus, after the land has been provided for parking, students and lecturers can now park there. But in reality the parking lot is still not able to accommodate two-wheeled vehicles of students, lecturers and employees for this research aims to analyze the needs of two-wheeled vehicle parking space on the campus of UNISKA MAB Banjarmasin.

Keywords: Analysis of Parking Space Needs of Two Wheeled Vehicles and Banjarmasin UNISKA MAB Campus

\section{PENDAHULUAN}

\section{Latar Belakang}

Banjarmasin sebagai salah satu kota dengan kepadatan penduduk yang cukup tinggi menyebabkan peningkatan dalam aspek trasportasi dengan setiap harinya kemacetan yang sering terjadi menandakan bahwa pemakaian kendaraan di kota banjarmasin meningkat dengan cepat, dengan meningkatnya volume lalu lintas kendaraan maka dibutuhkan suatu ruang parkir untuk kendaraan.

Universitas Islam Kalimantan Muhammad Arsyad Al Banjari (UNISKA MAB) Banjarmasin adalah salah satu tujuan daripada mahasiswa dari berbagai daerah, mulai dari kota Banjarmasin sendiri sampai dari luar kota, dengan demikian setiap mahasiswa, dosen dan karyawan menggunakan transportasi sendiri-sendiri, mulai dengan transportasi umum sampai kendaraan pribadi. Kendala dari salah satu transportasi tersebut adalah kendaraa pribadi, dimana UNISKA harus menyediakan ruang parkir untuk kendaraan mahasiswa, dosen dan karyawan. Semakin bertambahnya pengguna kendaraan pribadi maka semakin banyaknya ruang yang harus disediakan untuk kebutuhan parkir.

Sebelum adanya kebijakan pemerintah Kota Banjarmasin dalam hal ini Dinas Perhubungan Kota Banjarmasin melakukan pelarangan parkir dibahu jalan sepanjang Jalan Adhyaksa mengakibatkan semakin berkurangnya lahan parkir yang ada untuk mahasiswa, dosen dan karyawan.

Dari pihak kampus setelah disediakan lahan untuk parkir, kini mahasiswa dan dosen dapat parkir di tempat tersebut. Tetapi pada kenyataannya lahan parkir itu masih tidak mampu menampung kendaraan roda dua mahasiswa, dosen dan karyawan untuk itu penelitian ini bertujuan untuk menganalisis kebutuhan ruang parkir kendaraan roda dua di kampus UNISKA MAB Banjarmasin. 


\section{Identifikasi Masalah}

Berdasarkan uraian pada latar belakang dapat diidentifikasi sejumlah masalah dalam kebutuhan ruang parkir di Kampus Uniska MAB sebagai berikut:

a. Pertumbuhan penggunaan kendaraan roda dua oleh mahasiswa, dosen dan karyawan sangat tinggi.

b. Kapasitas ruang parkir kendaraan roda dua yang ada belum mencukupi sehingga sering digunakan badan jalan Adhyaksa menjadi parkir on street mengakibatkan hambatan samping menjadi besar.

c. Belum adanya penataan ruang parkir di kawasan Jalan Adhyaksa

d. Adanya penggunaan lalu lintas searah mulai dari simpang empat Jalan Sultan Adam ke Bundaran Kayu Tangi dikarenakan rekayasa lalu-lintas Dinas Perhubungan Kota Banjarmasin akibat proyek pembangunan Jembatan Alalak I.

\section{Rumusan Masalah}

Adapun rumusan masalah yaitu:

a. Bagaimana kegiatan parkir di UNISKA MAB Banjarmasin?

b. Berapa kapasitas lahan parkir UNISKA MAB Banjarmasin?

\section{Tujuan Penelitian}

Tujuan pengumpulan data pada survei parkir kali ini yaitu :

a. Untuk mengetahui jumlah kendaraan yang keluar masuk lahan parkir UNISKA MAB Banjarmasin (kondisi nyata di lapangan).

b. Untuk mengetahui kapasitas parkir sehingga akan mendapatkan kebutuhan ruang parkir UNISKA MAB Banjarmasin.

\section{Pembatasan Masalah}

Adapun pembatasan masalah dalam pengerjaan karya tulis ini sebagai berikut :

a. Melakukan survei lokasi parkir di beberapa area parkir UNISKA MAB Banjarmasin.

b. Menganalisis kapasitas area yang digunakan sebagai lahan parkir kendaraan roda dua.

c. Waktu yang dilakukan untuk survei jumlah kendaraan roda dua pada hari Rabu, 16 Oktober 2019 mulai dari pukul 08.00 s.d. 16.00 WITA.

\section{Lokasi Penelitian}

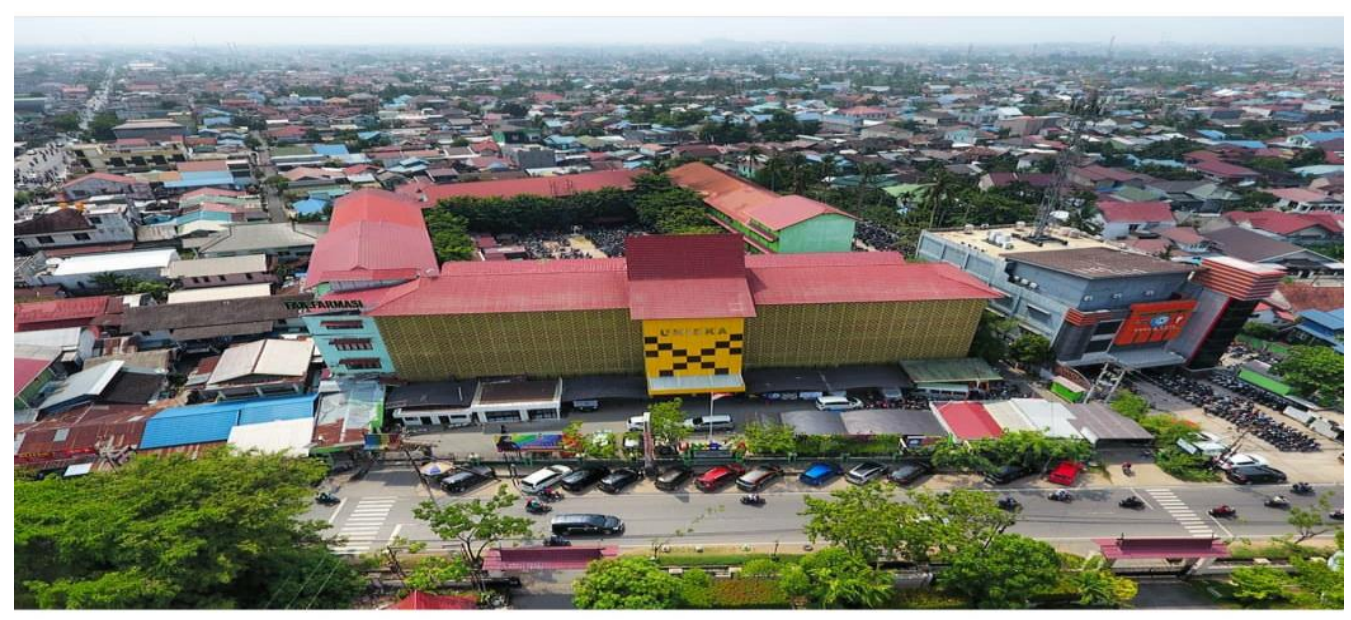

Gambar 1. Kampus UNISKA MAB Banjarmasin - Jalan Adhyaksa No.2 Sumber : koleksi pribadi dengan photo drone, 2019 


\section{TINJAUAN PUSTAKA}

Definisi Parkir: Parkir adalah kendaraan tidak bergerak suatu kendaraan yang tidak bersifat sementara (UU. RI. No 43. Th 1993). Sedangkan menurut Warpani (1990:157), parkir juga dapat didefinisikan sebagai suatu kendaraan yang berhenti untuk sementara (menurunkan muatan) atau berhenti cukup lama. Selanjunya "parkir adalah tempat khusus bagi kendaraan untuk berhenti demi keselamatan" (Ofyar, 2003).

Cara dan Jenis Parkir : Diklasifikasikan menurut berbagai macam hal, diantaranya adalah sebagai berikut :

Menurut Penempatan : Parkir dapat dibagi menjadi tiga yaitu; (1) parkir diluar jalan (off-street parking); (2) jenis-jenis parkir di luar jalan. Lebar tempat parkir yang direkomendasikan untuk parkir jangka lama adalah 2,30 m, dengan ukuran ini sudah tersedia jarak $0,55 \mathrm{~m}$ antara lebar dua mobil yang parkir berdekatan. Lebar yang direkomendasikan ini perlu ditambah hingga menjadi 2,5 m untuk menambah kemudahan berbelanja dan ini berlaku juga untuk tempat parkir yang memadai dengan ukuran 4,75 m, dengan jarak gang yang berdekatan $6 \mathrm{~m}$ bila sudut parkir $90^{\circ}$. Dengan demikian lebar minimum dari dua deretan parkir adalah 15,5 m. Ukuran ini diperoleh dari $(6 \mathrm{~m})$. Lebar deretan parkir ini biasa disebut bay width; a) pelataran parkir di permukaan tanah; b) garasi bertingkat; c) garasi bawah tanah; d) garasi gabungan bertingkat dan bawah tanah, dan; e) garasi mekanis. (3) parkir badan jalan (on-street parking).

Menurut Pengelolaan : Fasilitas parkir dapat diklasifikasikan sebagai berikut: a) parkir umum; b) parkir khusus; c) parkir darurat; d) parkir taman; e) parkir gedung. Menurut Jenis Kendaraan : Berdasarkan jumlah kendaraan yang mengisinya, fasilitas parkir terdiri dari: a) parkir kendaraan roda dua tidak bermotor; b) parkir kendaraan roda dua bermotor; c) parkir kendaraan roda empat atau lebih bermotor. Menurut Tujuan : Berdasarkan tujuan parkirnya, suatu fasilitas parkir dapat dibagi sebagai berikut: a) parkir penumpang; b) parkir barang.

Penyelenggara Parkir : Bertambahnya jumlah penduduk dan meningkatnya pemiliki kendaraan menambah permintaan akan ruas jalan untuk kegiatan lalu lintas. Fasilitas parkir untuk umum juga dapat befungsi sebagai salah satu alat pengendali lalu lintas, untuk memenuhi kebutuhan tersebut maka pada kawasankawasan tertentu dapat di sediakan kawasan parkir umum, yang diusahakan sebagai suatu kegiatan usaha yang berdiri sendiri dengan memungut bayaran.

Sarana Penyelenggara Parkir : a) Untuk mengendalikan jumlah kendaraan yang masuk kesuatu kawasan; b) meningkatkan pendapatan asli daerah yang dikumpul melalui retibusi parkir; c) meningkatkan fungsi jalan sehingga sesuai dengan perannya; d) meningkatkan kelancaran dan keselamatan lalu lintas, dan; e) mendukung tindakan pembatasan lalu lintas lainnya.

Kewenangan Penyelenggara Parkir : Pasal 11 ayat 2 Undang-Undang No. 14 tahun 1992 menyebutkan bahwa fasilitas parkir untuk umum kadapat diselenggarakan oleh pemerintah, badah hukum Indonesia, atau negara Indonesia. Dalam Keputusan Menteri Perhubungan No. 66 Tahun 1993 pasal 7 ayat 2 
dijelaskan bahwa izin penyelengaraan fasilitas parkir untuk umum dapat diselenggarakan untuk umum diberi oleh Bupati atau Walikota kepada daerah tingkat I. Berbeda dengan ketentuan yang berlaku sebelum ini didalam perturan pemerintahan No. 20 Tahun 1997 tentang Retribusi, retribusi parkir hanya dapat dilakukan di pinggir jalan dan pada tempat khusus parkir yang dimiliki atau dikelola oleh pemerintah daerah, sedangkan bagi pelataran atau gedung parkir tidak dapat dipungut oleh Pemerintah Daerah.

Penetapan Lokasi Parkir dan Penyelenggaraan Parkir : Penetapan lokasi dan pembangunan fasilitas parkir untuk umum dilakukan dengan memperhatikan: a) rencana umum tata ruang daerah; b) keselamatan dan kelancaran lalu lintas; c) kelestarian lingkungan; d) kemudahan bagi pengguna jasa. Penyelenggaraan fasilitas parkir untuk umum menurut peraturan perundangan yang berlaku dilakukan oleh: a) pemerintah; b) badan hukum Indonesia, dan; c) warga negara Indonesia

Layout Parkir : Ukuran panjang dan lebar ruang parkir biasanya disesuaikan dengan ukuran kendaraan yang parkir. Sedangkan ukuran kendaraan itu berbedabeda. Penentuan Satuan Ruang Parkir (SRP) tersebut dapat dilihat pada Tabel 1. di bawah ini:

Tabel 1. Penentuan SRP Berdasarkan Tipe Jalan

\begin{tabular}{|l|c|c|c|c|l|}
\hline \multicolumn{1}{|c|}{ Tipe Jalan } & $\begin{array}{c}\text { Kecepatan Min } \\
(\mathbf{k m} / \mathbf{j a m})\end{array}$ & $\begin{array}{c}\text { Lebar Badan } \\
\text { Jalan }(\mathrm{m})\end{array}$ & $\begin{array}{c}\text { Lokasi Parkir } \\
\text { Kendaraan }\end{array}$ & $\begin{array}{c}\text { Lokasi Berhenti } \\
\text { Kendaraan }\end{array}$ & $\begin{array}{c}\text { Lebar } \\
\text { Perkera san }\end{array}$ \\
\hline Arteri Primer & 60 & 8,00 & Tidak dijinkan & Tidak dijinkan & $\begin{array}{l}2 \times 7 \mathrm{~m} \\
2 \times 3 \mathrm{~m}\end{array}$ \\
\hline Arteri Sekunder & 30 & 8,00 & Dibatasi & Dibatasi & $\begin{array}{l}2 \times 7 \mathrm{~m} \\
2 \times 3 \mathrm{~m}\end{array}$ \\
\hline Kolektor Primer & 40 & 7,00 & Dibatasi & Dibatasi & $\begin{array}{l}2 \times 6,5 \mathrm{~m} \\
2 \times 2,5 \mathrm{~m}\end{array}$ \\
\hline Kolektor Sekunder & 20 & 7,00 & Dibatasi v & Dibatasi & $\begin{array}{l}2 \times 6,5 \mathrm{~m} \\
2 \times 2,5 \mathrm{~m}\end{array}$ \\
\hline Kolektor Primer & 40 & 7,00 & Dibatasi & Dibatasi & $\begin{array}{l}2 \times 6,5 \mathrm{~m} \\
2 \times 2,5 \mathrm{~m}\end{array}$ \\
\hline Kolektor Sekunder & 20 & 7,00 & Dibatasi & Dibatasi & $\begin{array}{l}2 \times 6,5 \mathrm{~m} \\
2 \times 2,5 \mathrm{~m}\end{array}$ \\
\hline Lokal Primer & 20 & 6,00 & & & $2 \times 3 \mathrm{~m}$ \\
\hline Lokal Sekunder & 10 & 5,00 & & & $2 \times 2,5 \mathrm{~m}$ \\
\hline
\end{tabular}

(Sumber : KD.No.272/HK.105/DRJD/96)

Sementara untuk penentuan Satuan Ruang Parkir (SRP) berdasarkan jenis kendaraan dapat dilihat pada Tabel 2.

Tabel 1. Penentuan SRP Berdasarkan Jenis Kendaraan

\begin{tabular}{|c|l|c|}
\hline No. & \multicolumn{1}{|c|}{ Jenis Kendaraan } & SRP dalam $\mathbf{~}^{2}$ \\
\hline \multirow{2}{*}{1.} & a. Mobil Penumpang Gol.I & $2,30 \times 5,00$ \\
\cline { 2 - 3 } & b. Mobil Penumpang Gol.II & $2,50 \times 5,00$ \\
\cline { 2 - 3 } & c. Mobil Penumpang Gol.III & $3,00 \times 5,00$ \\
\hline 2. & Bus/Truk & $3,40 \times 12,50$ \\
\hline 3. & Sepeda Motor & $0,75 \times 2,00$ \\
\hline
\end{tabular}

(Sumber : KD.No.272/HK.105/DRJD/96) 
Lebar jalan akses parkir adalah jalan atau ruang pada tempat parkir yang diperuntukkan bagi kendaraan bergerak sebelum dan sesudah parkir. Jalan akses ini sangat erat hubungannya dengan kemudahan pengendara yang akan memarkirkan sepeda motor atau untuk mencapai pintu keluar.

\section{Formula Kebutuhan Ruang Parkir :}

1. Survei luas lahan parkir kampus UNISKA MAB Banjarmasin di empat titik lokasi parkir A, B, C dan D.

2. Petak parkir kendaraan roda dua kondisi eksisting di lokasi A, B, C dan D Jumlah petak parkir kendaraan roda dua $=\frac{\text { Luas Lokasi Parkir }}{\text { SRP }}$

3. Akumulasi parkir untuk mengetahui jumlah kendaraan yang sedang berada pada suatu lahan parkir pada selang waktu tertentu.

Akumluasi Parkir $=\mathrm{Qp}$

Dimana :

Qp adalah jumlah kendaraan yang masuk lokasi parkir

4. Tingkat Penggunaan (TP) atau Occupancy Rate diperoleh dari akumulasi kendaraan pada selang waktu tertentu dibagi dengan ruang parkir yang tersedia dikalikan $100 \%$.

$\mathrm{TP}=\frac{\text { Akumulasi Parkir }}{\text { Ruang Parkir Tersedia }} \times 100 \%$

5. Volume Parkir/Kapasitas Parkir (Qp) adalah jumlah kendaraan yang telah menggunakan ruang parkir pada suatu lahan parkir tertentu dalam satu satuan waktu tertentu (biasanya per hari).

6. Durasi Parkir adalah untuk mengetahui lama suatu kendaraan.

Durasi Parkir $=\mathrm{T}$ total

Dimana :

T total adalah waktu saat kendaraan masuk lokasi parkir

7. Tingkat Pergantian Parkir atau Parking Turn Over diperoleh dari jumlah kendaraan yang telah memanfaatkan lahan parkir pada selang waktu tertentu dibagi dengan ruang parkir yang tersedia.

Parking Turn Over $=\frac{Q p}{\text { Petak } \text { Parkir Tersedia }}$

Dimana :

Qp adalah jumlah kendaraan yang telah berada di lokasi parkir.

8. Indeks Parkir (IP) adalah merupakan persentase dari akumulasi jumlah kendaraan pada selang waktu tertentu dibagi dengan ruang parkir yang tersedia dikalikan $100 \%$.

$$
\mathrm{IP}=\frac{(\text { Akumulasi Parkir } \mathrm{x} 100 \%)}{\text { Petak Parkir Tersedia }}
$$


9. Rata-rata Durasi Parkir (D) adalah nilai rata-rata lama waktu parkir dari semua kendaraan.

$$
\mathrm{D}=\frac{\mathrm{Qp}}{\text { Luas Parkir }}
$$

Dimana :

D adalah Rata-rata Durasi Parkir

10. Kebutuhan/Jumlah Ruang Parkir yang dibutuhkan.

$$
\mathrm{Z}=\frac{\text { Jumlah kendaraan } \mathrm{x} \text { Rata }- \text { rata durasi parkir }}{\text { Periode waktu parkir (waktu pengamatan ) }}
$$

Dimana : $Z=\frac{\text { Qp X D }}{T}$

Z : Kebutuhan/Jumlah Ruang Parkir yang dibutuhkan

Qp : jumlah kendaraan yang pakir per waktu tertentu

D : Rata-rata durasi parkir (jam)

$\mathrm{T}$ : Periode waktu parkir/waktu pengamatan (jam)

\section{METODE PENELITIAN}

Metode yang digunakan dalam penelitian ini adalah survei kendaraan roda dua yang parkir di kampus UNISKA MAB Banjarmasin kemudian dianalisis dengan perhitungan kebutuhan ruang parkir kendaraan roda dua. Sehingga dapat disimpulkan bahwa metode survei kendaraa roda dua yang parkir dan menghitung kebutuhan ruang parkir kampus UNISKA MAB Banjarmasin adalah sebuah cara atau teknik yang dilakukan untuk memaparkan suatu permasalahan sehingga dapat dengan jelas dianalisis dan ditarik kesimpulan. Dapat dilihat Diagram Alir Penelitian bisa dilihat pada Gambar 2. 
JURNAL KACAPURI

JURNAL KEILMUAN TEKNIK SIPIL

Volume 2 Nomor 2 Edisi Desember 2019

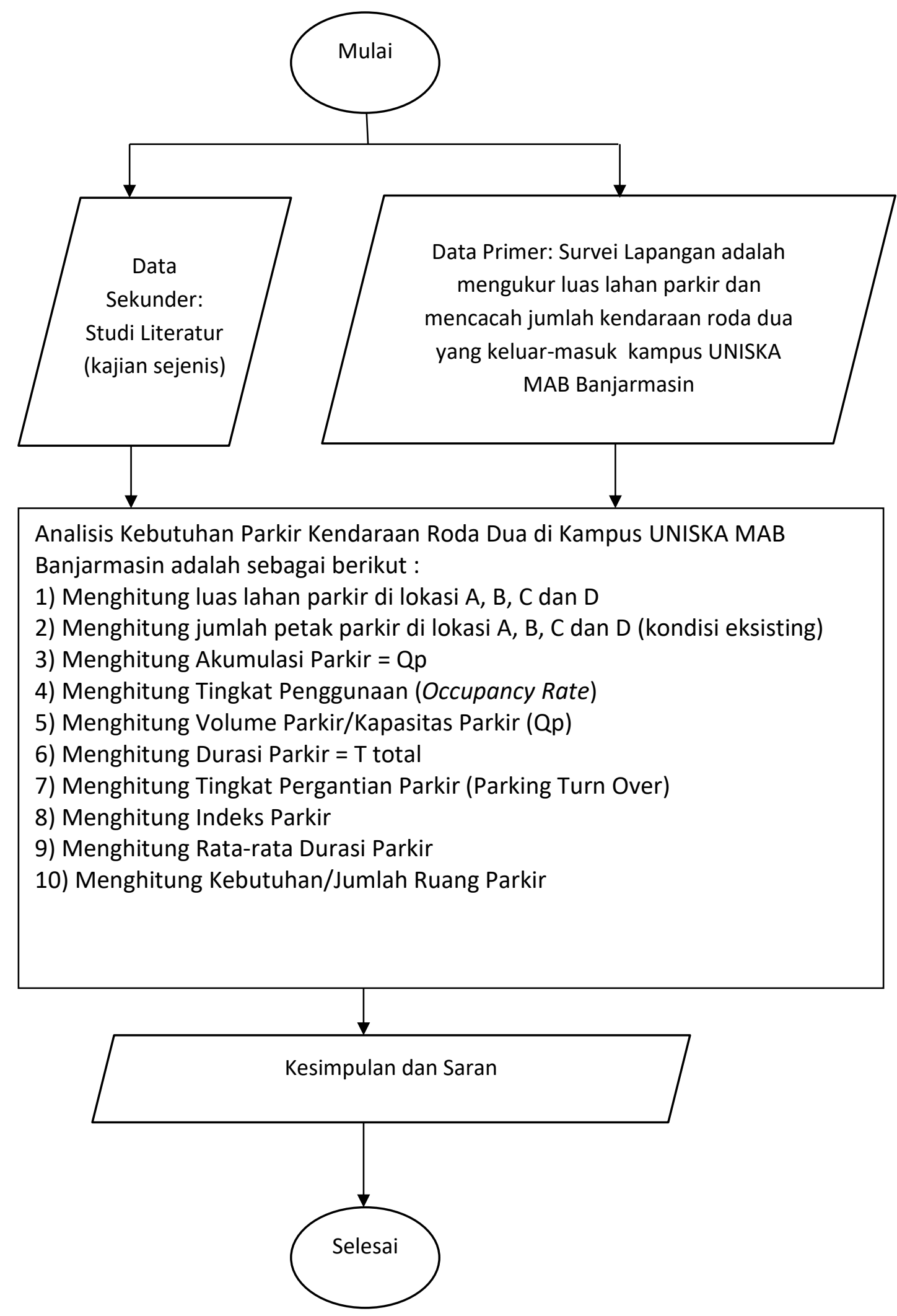

Gambar 2. Diagram Alir Penelitian

Sumber : Analisis, 2019 


\section{HASIL DAN PEMBAHASAN}

\section{Hasil survei kendaraan roda dua yang keluar masuk Kampus Uniska MAB}

Survei lapangan dilakukan dalam satu hari mulai pukul 08.00 s.d. 16.00 wita. Ada empat titik lokasi parkir kampus UNISKA MAB. Lokasi A, B, C dan D. Adapun hasilnya dapat dilihat Tabel 3.

Tabel 3. Data Survei Keluar Masuk Kendaraan R2 di Kampus UNISKA MAB

\begin{tabular}{|c|c|r|r|}
\hline \multicolumn{3}{|c|}{ Data Survei Keluar Masuk Kendaraan R2 } \\
\hline Lokasi & Waktu (Durasi) & \multicolumn{2}{|c|}{ Data } \\
\cline { 3 - 4 } & & Masuk & Keluar \\
\hline 1 & $08.00-09.00$ & 248 & 30 \\
\hline 2 & $09.00-10.00$ & 171 & 96 \\
\hline 3 & $10.00-11.00$ & 122 & 169 \\
\hline 4 & $11.00-12.00$ & 160 & 238 \\
\hline 5 & $12.00-13.00$ & 97 & 167 \\
\hline 6 & $13.00-14.00$ & 220 & 116 \\
\hline 7 & $14.00-15.00$ & 190 & 117 \\
\hline 8 & $15.00-16.00$ & 120 & 150 \\
\hline \multicolumn{2}{|c|}{ Jumlah Kendaraan R2 } & 1328 & 1083 \\
\hline
\end{tabular}

\begin{tabular}{|c|c|r|r|}
\hline \multicolumn{3}{|c|}{ Data Survei Keluar Masuk Kendaran R2 } \\
\hline $\begin{array}{c}\text { Lokasi } \\
\text { B }\end{array}$ & Waktu (Durasi) & \multicolumn{2}{|c|}{ Data } \\
\cline { 3 - 4 } & Masuk & Keluar \\
\hline 1 & $08.00-09.00$ & 215 & 16 \\
\hline 2 & $09.00-10.00$ & 68 & 24 \\
\hline 3 & $10.00-11.00$ & 87 & 49 \\
\hline 4 & $11.00-12.00$ & 75 & 42 \\
\hline 5 & $12.00-13.00$ & 84 & 21 \\
\hline 6 & $13.00-14.00$ & 166 & 13 \\
\hline 7 & $14.00-15.00$ & 142 & 58 \\
\hline 8 & $15.00-16.00$ & 79 & 43 \\
\hline \multicolumn{2}{|c|}{ Jumlah Kendaraan R2 } & 916 & 266 \\
\hline
\end{tabular}

\begin{tabular}{|c|c|r|r|}
\hline \multicolumn{3}{|c|}{ Data Survei Keluar Masuk Kendaraan R2 } \\
\hline $\begin{array}{c}\text { Lokasi } \\
\text { C }\end{array}$ & Waktu (Durasi) & \multicolumn{2}{|c|}{ Data } \\
\cline { 2 - 4 } & & Masuk & Keluar \\
\hline 1 & $08.00-09.00$ & 45 & 56 \\
\hline 2 & $09.00-10.00$ & 43 & 70 \\
\hline 3 & $10.00-11.00$ & 43 & 161 \\
\hline 4 & $11.00-12.00$ & 13 & 230 \\
\hline 5 & $12.00-13.00$ & 11 & 186 \\
\hline 6 & $13.00-14.00$ & 22 & 62 \\
\hline 7 & $14.00-15.00$ & 19 & 150 \\
\hline 8 & $15.00-16.00$ & 9 & 107 \\
\hline \multicolumn{2}{|c|}{ Jumlah Kendaraan R2 } & 205 & 1022 \\
\hline
\end{tabular}

\begin{tabular}{|c|c|r|r|}
\hline \multicolumn{3}{|c|}{ Data Survei Keluar Masuk Kendaraan R2 } \\
\hline \multirow{2}{*}{$\begin{array}{c}\text { Lokasi } \\
\text { D }\end{array}$} & Waktu (Durasi) & \multicolumn{2}{|c|}{ Data } \\
\cline { 2 - 4 } & & Masuk & Keluar \\
\hline 1 & $08.00-09.00$ & 19 & 5 \\
\hline 2 & $09.00-10.00$ & 15 & 4 \\
\hline 3 & $10.00-11.00$ & 13 & 6 \\
\hline 4 & $11.00-12.00$ & 4 & 8 \\
\hline 5 & $12.00-13.00$ & 3 & 5 \\
\hline 6 & $13.00-14.00$ & 6 & 6 \\
\hline 7 & $14.00-15.00$ & 12 & 15 \\
\hline 8 & $15.00-16.00$ & 34 & 21 \\
\hline \multicolumn{2}{|l}{ Jumlah Kendaraan R2 } & 106 & 70 \\
\hline
\end{tabular}

(Sumber : Hasil survei, 2019)

Dari Tabel 3 didapatkan sebagai berikut :

1. Jumlah kendaraan roda dua masuk di lokasi A selama 8 jam sebesar 1328 kendaraan.

2. Jumlah kendaraan roda dua keluar di lokasi A selama 8 jam sebesar 1083 kendaraan.

3. Jumlah kendaraan roda dua masuk di lokasi B selama 8 jam sebesar 916 kendaraan.

4. Jumlah kendaraan roda dua keluar di lokasi B selama 8 jam sebesar 266 
5. Jumlah kendaraan roda dua masuk di lokasi C selama 8 jam sebesar 205 kendaraan.

6. Jumlah kendaraan roda dua keluar di lokasi C selama 8 jam sebesar 1022 kendaraan.

7. Jumlah kendaraan roda dua masuk di lokasi D selama 8 jam sebesar 106 kendaraan.

8. Jumlah kendaraan roda dua keluar di lokasi D selama 8 jam sebesar 70 kendaraan.

\section{Hasil survei luas lahan parkir Kampus UNISKA MAB}

Ada empat lokasi parkir yang disiapkan oleh Kampus UNISKA MAB yaitu lokasi A, B, C dan D dapat dilihat Gambar 3.

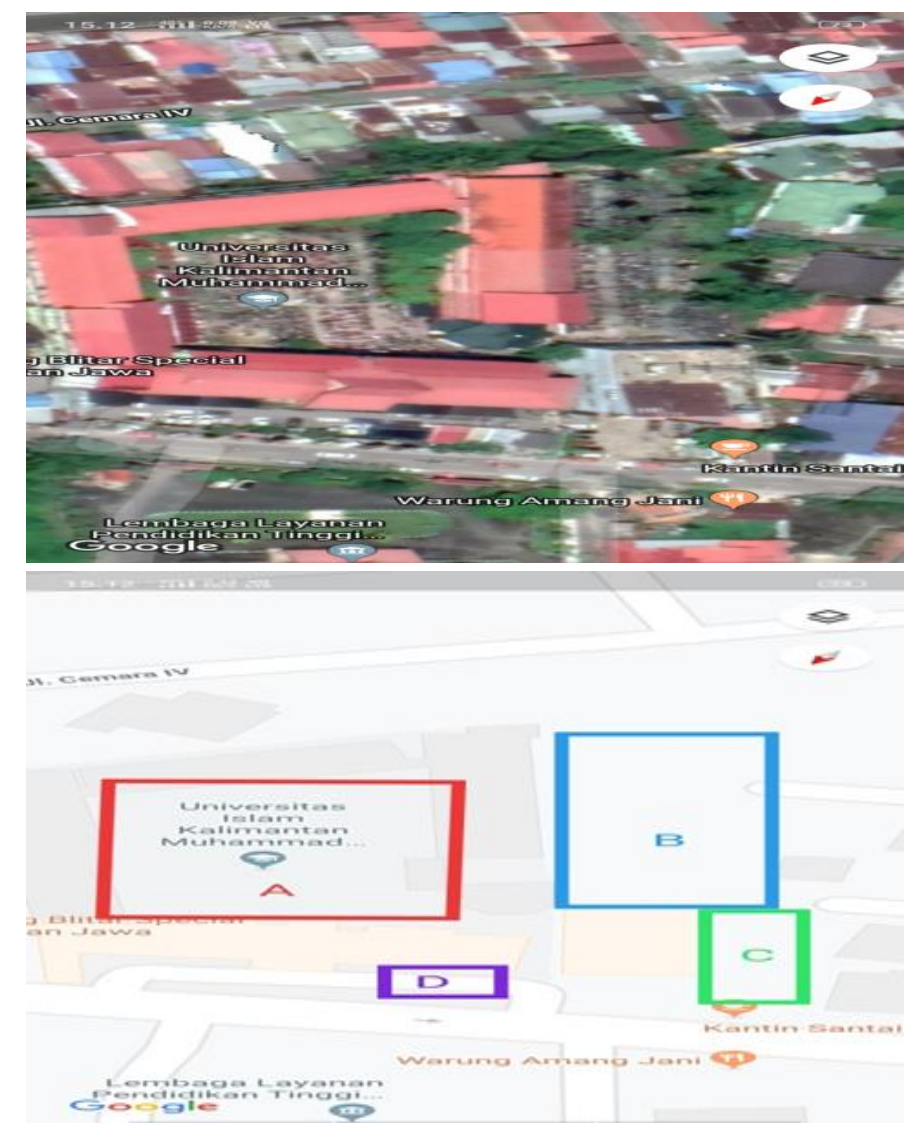

Gambar 3. Lokasi Parkir Kampus UNISKA MAB Banjarmasin Sumber : https://www.google.com/intl/id/earth/

Hasil survei luas lahan parkir kampus UNISKA MAB Banjarmasin sebagai berikut :

1. Luas lokasi parkir $A=1917 \quad \mathrm{~m}^{2}$

2. Luas lokasi parkir $B=1105 \mathrm{~m}^{2}$

3. Luas lokasi parkir $\mathrm{C}=305.50 \mathrm{~m}^{2}$

4. Luas lokasi parkir $\mathrm{D}=60 \quad \mathrm{~m}^{2}$ 


\title{
Petak Parkir Kendaraan Roda Dua Kondisi Eksisting
}

Petak Parkir Kendaraan Roda Dua $=\frac{\text { Luas Lokasi Parkir }}{\text { SRP }}$

1. Petak Parkir Kendaraan Roda Dua di lokasi $A=\frac{1917}{1.5}=1278$ kend/petak 1278

2. Petak Parkir Kendaraan Roda Dua di lokasi $B=\frac{1105}{1.5}=736$ kend $/$ petak 736

3. Petak Parkir Kendaraan Roda Dua di lokasi C $=\frac{305.5}{1.5}=203$ kend/petak 203

4. Petak Parkir Kendaraan Roda Dua di lokasi $\mathrm{D}=\frac{60}{1.5}=40 \mathrm{kend} / \mathrm{petak} 40$

\begin{abstract}
Akumulasi Parkir
Akumulasi Parkir $=$ Qp

1. Akumulasi Parkir di lokasi $\mathrm{A}=1328$ kendaraan roda dua

2. Akumulasi Parkir di lokasi $\mathrm{B}=916$ kendaraan roda dua

3. Akumulasi Parkir di lokasi $\mathrm{C}=205$ kendaraan roda dua

4. Akumulasi Parkir di lokasi $\mathrm{D}=106$ kendaraan roda dua
\end{abstract}

Tingkat Penggunaan (TP) atau Occupancy Rate

$\mathrm{TP}=\frac{\text { Akumulasi Parkir }}{\text { Luas Lokasi Parkir }} x 100 \%$

1. TP Parkir di lokasi $\mathrm{A}=\frac{245}{1917} \times 100 \%=12.78 \%$

2. TP Parkir di lokasi $\mathrm{B}=\frac{650}{1105} \times 100 \%=58.82 \%$

3. TP Parkir di lokasi $\mathrm{C}=\frac{817}{305.50} \times 100 \%=267.43 \%$

4. TP Parkir di lokasi $\mathrm{D}=\frac{36}{60} x 100 \%=60 \%$

\section{Volume Parkir /Kapasitas Parkir (Qp)}

Volume Parkir = Jumlah kendaraan yang parkir dalam satuan waktu (masuk)

1. Volume Parkir di lokasi A selama 8 jam $=1328$ kendaraan roda dua

2. Volume Parkir di lokasi B selama 8 jam $=916$ kendaraan roda dua

3. Volume Parkir di lokasi $\mathrm{C}$ selama 8 jam $=205$ kendaraan roda dua

4. Volume Parkir di lokasi D selama 8 jam $=106$ kendaraan roda dua

\section{Durasi Parkir}

Durasi Parkir $=\mathrm{T}$ total

1. Durasi Parkir di lokasi $\mathrm{A}=8$ jam

2. Durasi Parkir di lokasi $\mathrm{B}=8$ jam

3. Durasi Parkir di lokasi $\mathrm{C}=8$ jam

4. Durasi Parkir di lokasi $\mathrm{D}=8$ jam 


\section{Tingkat Pergantian Parkir atau Parking Turn Over}

Parking Turn Over $=\frac{Q p}{\text { Petak Parkir Tersedia }}$

1. PTO di lokasi $\mathrm{A}=\frac{1328}{1278}=1.04$

2. PTO di lokasi $\mathrm{B}=\frac{916}{736}=1.25$

3. PTO di lokasi $\mathrm{C}=\frac{205}{203}=1.01$

4. PTO di lokasi $\mathrm{D}=\frac{106}{40}=2.65$

\section{Indeks Parkir (IP)}

$\mathrm{IP}=\frac{(\text { Akumulasi Parkir } x 100 \%)}{\text { Petak Parkir Tersedia }}$

1. IP lokasi $\mathrm{A}=\frac{(245 * 100 \%)}{1278}=0.19$

2. IP lokasi $\mathrm{B}=\frac{(650 * 100 \%)}{736}=0.89$

3. IP lokasi $\mathrm{C}=\frac{(-817 * 100 \%)}{203}=-4.03$

4. IP lokasi $\mathrm{D}=\frac{(36 * 100 \%)}{40}=0.90$

\section{Rata-rata Durasi Parkir (D)}

$\mathrm{D}=\frac{\text { Jumlah Kendaraan Parkir }}{\text { Luas Parkir }}$

1. Rata-rata durasi parkir lokasi $\mathrm{A}, \mathrm{D}=\frac{1328}{1917}=0.69$ jam $=(41$ menit $)$

2. Rata-rata durasi parkir lokasi $\mathrm{B}, \mathrm{D}=\frac{916}{1105}=0.83 \mathrm{jam}=(50 \mathrm{menit})$

3. Rata-rata durasi parkir lokasi $\mathrm{C}, \mathrm{D}=\frac{205}{305.5}=0.67$ jam $=(40$ menit $)$

4. Rata-rata durasi parkir lokasi $\mathrm{D}, \mathrm{D}=\frac{106}{60}=1.76$ jam $=(106 \mathrm{menit})$

\section{Kebutuhan/Jumlah Ruang Parkir Yang Dibutuhkan}

$\mathrm{Z}=\frac{Q p * D}{T}$ 

1. Kebutuhan Ruang Parkir A, $\mathrm{Z}=\frac{1328 \times 0.69}{8}=114.54=114$ Kendaraan
2. Kebutuhan Ruang Parkir B, $\mathrm{Z}=\frac{916 \times 0.83}{8}=95.04=95$ Kendaraan
3. Kebutuhan Ruang Parkir C, $\mathrm{Z}=\frac{205 \times 0.67}{8}=17.17=17$ Kendaraan
4. Kebutuhan Ruang Parkir D, $\mathrm{Z}=\frac{106 \times 1.76}{8}=23.32=23 \mathrm{Kendaraan}$

\section{PENUTUP}

\section{Kesimpulan}

Dari hasil perhitungan dan analisis yang dilakukan dapat disimpulkan sebagai berikut :

1. Dari hasil survey yang dilakukan bahwa, kendaraan masuk paling banyak pada pagi hari pukul 08.00 s.d 10.00 wita dan pada siang hari pukul 13.00 s.d 15.00 wita

2. Sedangkan untuk kendaraan yang keluar paling banyak pada pagi hari pukul 10.00 s.d 12.00 wita dan pada siang hari pada pukul 14.00 s.d 16.00 wita.

3. Rata-rata durasi dari pemakaian lahan parkir di empat lokasi parkir adalah 59 menit.

4. Dan rata-rata kebutuhan parkir kendaraan roda dua dari empat area parkir adalah 62 kendaraan roda dua.

5. Kebutuhan parkir sebagai berikut :

- Lokasi parkir A adalah 114 kendaraan/petak

- Lokasi parkir B adalah 95 kendaraan/petak

- Lokasi parkir C adalah 17 kendaraan/petak

- Lokasi parkir D adalah 23 kendaraan/petak

6. Kapasitas parkir dengan kondisi eksisting sebagai berikut :

- Lokasi parkir A adalah 1278 kendaraan/petak

- Lokasi parkir B adalah 736 kendaraan/petak

- Lokasi parkir C adalah 203 kendaraan/petak

- Lokasi parkir D adalah 40 kendaraan/petak

7. Kapasitas parkir masih mampu menampung kebutuhan parkir pada masa penelitian tahun 2019.

\section{Saran}

Sebagai bahan untuk meningkatkan analisis terhadap tempat parkir sebaiknya dilakukan survei dengan durasi yang lebih lama misalkan dengan hitungan hari. Dan untuk mendapatkan hasil yang lebih baik perlu dilakukan adanya survei wawancara kepada pengguna tempat parkir. 


\section{Ucapan Terimakasih}

Penulis mengucapkan terimakasih kepada kawan-kawan dosen Universitas Islam Kalimantan Muhammad Arsyad Al Banjari Banjarmasin, mahasiswa prodi (S-1) Teknik Sipil UNISKA MAB serta semua pihak yang telah banyak membantu kelancaran dan selesainya penelitian ini.

\section{DAFTAR PUSTAKA}

Departemen Perhubungan. 1993. Pedoman Perencanaan dan Pengoperasian fasilitas Parkir, Direktorat Bina Sistem Lalu Lintas Angkutan Kota, Direktorat Jenderal Perhubungan Darat, Jakarta.

Departemen Perhubungan. 1996. Pedoman Perencanaan dan Pengoperasian fasilitas Parkir, Direktorat Bina Sistem Lalu Lintas Angkutan Kota, Direktorat Jenderal Perhubungan Darat, Jakarta.

Departemen Perhubungan. 1998. Pedoman Perencanaan dan Pengoperasian fasilitas Parkir, Direktorat Bina Sistem Lalu Lintas Angkutan Kota, Direktorat Jenderal Perhubungan Darat, Jakarta.

Sugiyono. 2002. Statistika Untuk Penelitian. Bandung: CV. Alfabeta.

Tamin, Ovyar Z. 2003. Perencanaan dan Pemodelan Transportasi (Contoh Soal dan Aplikasi). Bandung: ITB.

Admin. 2012. Importance Performance Analysis (IPA). Ensiklopedia. Usulan Perbaikan Layanan Diklat Teknik Pusdiklat Mineral Dan Batu Bara Dengan Dimensi Student Statification Inventory (SSI) dan Metode Lean Sigma

Wahyuni, Rida. 2008. Pengaruh Parkir pada Badan Jalan terhadap Kinerja Ruas Jalan. Sumatera Utara: Universitas Sumatera Utara

Suwardi. 2000. Diktat Mata Kuliah Angkutan Umum, Surakarta: Universitas Muhammadiyah Surakarta.

Arikunto, Suharmusi. 2006. Prosedur Penelitian Suatu Pendekatan Praktik. Jakarta: PT Rineka Cipta.

Sukanadarummidi. 2002. Metode Penelitian dan Pedoman Penulisan Skripsi. Yogyakarta: Andi Offset

Sugiyono. 2002. Statistika Untuk Penelitian. Bandung: CV. Alfabeta. 